\title{
DOUTORADO PROFISSIONAL E NOVOS DESAFIOS NA PRODUÇÃO E TRANSFERÊNCIA DE CONHECIMENTO NA ÁREA DE ENFERMAGEM
}

\author{
PROFESSIONAL DOCTORATE AND THE NEW \\ CHALLENGES IN KNOWLEDGE PRODUCTION AND \\ TRANSFER IN THE NURSING AREA
}

\section{DOCTORADO PROFESIONAL Y LOS NUEVOS DESAFÍOS EN LA PRODUCCIÓN Y TRANSFERENCIA DEL CONOCIMIENTO EN EL ÁREA DE ENFERMERÍA}

\author{
Alacoque Lorenzine Erdmann ${ }^{1}$
}

Como citar este artigo: Erdmann AL. Doutorado Profissional e novos desafios na produção e transferência de conhecimento na área de enfermagem. Rev baiana enferm. 2019;33:e33893.

Alinhado com as políticas públicas de ensino superior, em 2017, a Portaria n. $389^{(1)}$, da Coordenação de Aperfeiçoamento de Pessoal de Nível Superior (CAPES), institui o doutorado profissional, quase duas décadas após o mestrado profissional, que surgiu nos anos 2000. Esses visam atender às demandas sociais, tecnológicas, organizacionais, profissionais e do mercado de trabalho, preenchendo lacunas dos cursos de mestrado e doutorado acadêmicos, criados na década de 70 e 80 , respectivamente.

O Doutorado Profissional em Gestão do Cuidado em Enfermagem, vinculado à Universidade Federal de Santa Catarina, está entre os sete primeiros aprovados no Brasil durante a 182a reunião do Conselho Técnico Científico da Educação Superior ${ }^{(2)}$. Seguramente tem-se novos desafios na consolidação do doutorado profissional, no que se refere à articulação integrada da formação profissional com diferentes entidades de ensino e saúde, visando melhorar a eficácia e a eficiência dessas organizações públicas e privadas e a produção e transferência do conhecimento produzido para a sociedade.

A formação de Mestres e Doutores Profissionais será voltada a desenvolver habilidades e competências de perfil diferenciado do Acadêmico, uma vez que está centrada em linhas específicas e articuladas ao domínio da prática profissional em um campo de atuação determinado. Essa instrumentalização especializada requer expertises metodológicas para a pesquisa aplicada e o desenvolvimento de produtos no campo da prática profissional, frutos não só dos laboratórios de pesquisa e tecnologia existentes nas unidades acadêmicas, como também de novas estruturas de pesquisa clínica ou de cuidados de enfermagem e saúde junto às instituições de serviços de saúde ${ }^{(3)}$.

Enfermeira. Bacharela em Desenho e Plástica. Doutora em Filosofia da Enfermagem. Professora da Universidade Federal de Santa Catarina. Florianópolis, Santa Catarina, Brasil. alacoque@newsite.com.br. https://orcid.org/0000-0003-4845-85। 5 
Os egressos desses cursos deverão ser dotados de capacidade de argumentação na sustentação de suas ideias/criações: sistematização, modelos, processos, protocolos, técnicas, produtos, registro das produções e de propriedades intelectuais e patentes, instrumentos e processos de divulgação/socialização, como está previsto no perfil, nos objetivos e nos modelos pedagógicos dos respectivos cursos.

Para tanto, está previsto o desenvolvimento de competências e habilidades, a exemplo de: domínio de técnicas de coordenação de equipes e de empreendimentos voltados para a geração de processos e produtos e sua utilização na prática; métodos e técnicas de avaliação de impacto; domínio de técnicas educativas e de capacitação dos demais profissionais da área de enfermagem para a leitura, compreensão e transferência de conhecimentos ou saberes para a sua prática profissional do cuidado. O que exige da(o)s enfermeira(o)s domínio e compartilhamento com as demais categorias profissionais da área de enfermagem, da pesquisa aplicada, que implica na produção, implementação e avaliação contínua de novas práticas que sustentem as práticas profissionais e atendam à complexidade da atenção à saúde de modo interdisciplinar, incluindo as demandas sociais, políticas e organizacionais do Sistema Único de Saúde.

Desse modo é esperado, com esse novo perfil de formação, que haja um incremento na produção e transferência de conhecimentos produzidos, para a criação e aplicação de processos tecnológicos e de inovação voltados para as práticas profissionais, além do alcance de impactos mais diretos na melhoria do cuidado de enfermagem em diferentes cenários nacionais e internacionais. O perfil dos autores, sua formação e domínio do conhecimento produzido, a exemplo dos conhecimentos e saberes tecnológicos, gerará novas estruturas e formas de textos a serem publicados, além do maior acesso e leitura das publicações em periódicos científicos, especialmente pela(o)s enfermeira(o)s vinculada(o)s aos serviços de atenção à saúde ${ }^{(4)}$.

Nessa perspectiva, o desafio está na participação efetiva dos periódicos da área de enfermagem com abertura de espaços e diálogo na comunidade científica e tecnológica, para a percepção, interpretação e prospecção de oportunidades de avanços para publicações, além das experiências de construção de novas práticas que são produtos inovadores e cuja estrutura de texto pode se diferenciar dos estudos teóricos e filosóficos, mas mantendo o mesmo rigor teórico e metodológico. Ademais, identificar e promover novos caminhos na transferência de conhecimentos da(o) enfermeira(o) e de geração de tecnologias avançadas, visando sua distinção científica e tecnológica, inserção social, consolidação e fortalecimento da sua identidade como profissão.

Cumprimenta-se a Enfermagem brasileira, pelos avanços já conquistados, certa de que o reconhecimento e a valorização da profissão enfermeira(o) será fruto de uma prática profissional sustentada na ciência e em tecnologias diferenciadas e altamente resolutivas, acompanhando e competindo com as melhores práticas de desenvolvimento tecnológico de outros continentes, incorporando os desafios das interações humanas, sociais e éticas do sentido e valor da vida e da natureza.

À Revista Baiana de Enfermagem, os votos de que siga conquistando novas indexações pelos méritos de trajetória de contribuições para a Enfermagem do Nordeste, brasileira e da América Latina e perspectivas de temáticas que despertem o interesse cada vez maior, especialmente dos pesquisadores, profissionais e estudantes da enfermagem, da saúde e da comunidade em geral.

\section{Referências}

1. Coordenação de Aperfeiçoamento de Pessoal de Nível Superior. Portaria 389, de 23 de março de 2017. Prorroga o prazo concedido pela Portaria MEC n ${ }^{\circ} 1.470$, de 20 de dezembro de 2016, que institui o Grupo de Trabalho de Simplificação Administrativa - GTSA para discutir medidas de simplificação administrativa sobre matérias correlatas ao Ministério da Educação - MEC e suas entidades vinculadas e supervisionadas [Internet]. Brasília; 2017 [cited 2019 out 19] Available from: http://www.capes.gov.br/tutorial-sucupira/documentos/Portaria389-2017_ doutoradoprofissional.pdf 
2. Coordenação de Aperfeiçoamento de Pessoal de Nível Superior. Resultado da Avaliação de Propostas de Cursos Novos [Internet]. Brasília, DF; 2014 [cited 2019 Oct 19]. Available from: http://www.capes.gov.br/avaliacao/ entrada-no-snpg-propostas/resultados.

3. Danielsen RD. The professional doctorate: what are we waiting for? Clin Rev. 2017 June;27(6):7-9.

4. Smith N-J. Professional doctorates and nursing practice contribution: a systematic literature search and descriptive synthesis. J Nurs Manag. 2012 ago;21(2):314-26. DOI: http://dx.doi.org/10.1111/j.1365-2834.2012.01446.x

Recebido: 21 de outubro de 2019

Aprovado: 21 de outubro de 2019

Publicado: 16 de dezembro de 2019

A Revista Baiana de Enfermagem utiliza a Licença Creative Commons - Atribuição-NãoComercial 4.0 Internacional. https://creativecommons.org/licenses/by-nc/4.0/

Este artigo é de acesso aberto distribuído sob os termos da Licença Creative Commons (CC BY-NC). Esta licença permite que outros remixem, adaptem e criem a partir do seu trabalho para fins não comerciais. Embora os novos trabalhos tenham de lhe atribuir o devido crédito e não possam ser usados para fins comerciais, os usuários não têm de licenciar esses trabalhos derivados sob os mesmos termos. 